\title{
Comparison of online marketing techniques on food and beverage companies' websites in six countries
}

\author{
Marie A. Bragg ${ }^{1,2^{*}}$ D, Margaret Eby ${ }^{1}$, Josh Arshonsky ${ }^{1,2}$, Alex Bragg ${ }^{1,2}$ and Gbenga Ogedegbe ${ }^{1,2}$
}

\begin{abstract}
Food and beverage marketing contributes to poor dietary choices among adults and children. As consumers spend more time on the Internet, food and beverage companies have increased their online marketing efforts. Studies have shown food companies' online promotions use a variety of marketing techniques to promote mostly energy-dense, nutrient-poor products, but no studies have compared the online marketing techniques and nutritional quality of products promoted on food companies' international websites. For this descriptive study, we developed a qualitative codebook to catalogue the marketing themes used on 18 international corporate websites associated with the world's three largest fast food and beverage companies (i.e. Coca-Cola, McDonald's, Kentucky Fried Chicken). Nutritional quality of foods featured on those websites was evaluated based on quantitative Nutrient Profile Index scores and food category (e.g. fried, fresh). Beverages were sorted into categories based on added sugar content. We report descriptive statistics to compare the marketing techniques and nutritional quality of products featured on the company websites for the food and beverage company websites in two high-income countries (HICs), Germany and the United States, two upper-middle-income countries (UMICs), China and Mexico, and two lower-middle-income countries (LMICs), India and the Philippines. Of the 406 screenshots captured from company websites, 67.8\% depicted a food or beverage product. HICs' websites promoted diet food or beverage products/healthier alternatives (e.g. baked chicken sandwich) significantly more often on their pages (25\%), compared to LMICs (14.5\%). Coca-Cola featured diet products significantly more frequently on HIC websites compared to LMIC websites. Charities were featured more often on webpages in LMICs (15.4\%) compared to UMICs (2.6\%) and HICs (2.3\%). This study demonstrates that companies showcase healthier products in wealthier countries and advertise their philanthropic activities in lower income countries, which is concerning given the negative effect of nutrition transition (double burden of overnutrition and undernutrition) on burden of non-communicable diseases and obesity in lower income countries.
\end{abstract}

Keywords: Obesity, Food marketing, International

\section{Introduction}

Poor dietary intake is associated with obesity [1]. Exposure to food and beverage marketing leads adults and children to increase short-term food consumption [2-4]. Although television food commercials continue to be a dominant source of exposure to food ads, food companies have increased their digital marketing presence as consumers spend more time online [5, 6]. Digital food

\footnotetext{
* Correspondence: marie.bragg@nyumc.org

${ }^{1}$ Department of Population Health, New York University School of Medicine, 227 East 30th Street Room 622, New York, NY 10016, USA

${ }^{2}$ New York University College of Global Public Health, 665 Broadway, 11th

Floor, New York, NY 10003, USA
}

marketing includes advertising through online advergames (e.g. website games intended to promote a brand), $[7,8]$ placement of ads on websites popular among specific demographic groups (e.g. children), [9-12] promotion of food products on branded websites, $[13,14]$ as well as through mobile devices and social media websites (e.g. Facebook) $[15,16]$. These studies have shown that the majority of foods promoted on websites are energydense, nutrient-poor foods, $[9-13,16]$ and children who play online advergames are more likely to consume nutrient-poor snack foods and fewer fruits and vegetables, [7] and increase energy intake regardless of the health profile of the product being advertised [17].

\section{Biomed Central}

(c) The Author(s). 2017 Open Access This article is distributed under the terms of the Creative Commons Attribution 4.0 International License (http://creativecommons.org/licenses/by/4.0/), which permits unrestricted use, distribution, and reproduction in any medium, provided you give appropriate credit to the original author(s) and the source, provide a link to the Creative Commons license, and indicate if changes were made. The Creative Commons Public Domain Dedication waiver (http://creativecommons.org/publicdomain/zero/1.0/) applies to the data made available in this article, unless otherwise stated. 
Most digital food marketing studies have been conducted in the United States, despite increases in the promotion and sales of fast food and sugar sweetened beverages globally [18]. McDonald's currently operates in more than 20,335 locations outside the United States, and it plans to open 3000 additional restaurants by 2020 with more than 1500 in China, Hong Kong, and South Korea $[19,20]$. Similarly, Coca-Cola pledged to spend $\$ 5$ billion in India on new plants and sales networks and a total of $\$ 17$ billion in Africa by 2020 to increase its presence $[21,22]$. Simultaneously, rates of obesity have risen in low- and middle-income countries, particularly among children and adolescents in developing countries, who have experienced an increased prevalence of overweight and obesity from 8.1 to $12.9 \%$ for boys and from 8.4 to $13.4 \%$ in girls [23]. One study showed a positive correlation between the number of Subway restaurants in a country and their national obesity rates [24]. Though that study is correlational and focused solely on lower-middle to higher income countries, the nutrition transition (i.e., moving from healthier, traditional and local foods, to more unhealthy Westernized diets) has led a number of health organizations to warn consumers of the damaging health effects associated with heavily processed energy-dense, nutrient-poor foods in contributing to the rise in global burden of obesity [25, 26]. Such warnings are strikingly similar to those resulting from the globalization of tobacco marketing, when tobacco companies began to market to developing countries in the 1970s after enforcement of stricter tobacco regulations in the U.S. [27].

Despite these warnings, there is little data on the variation in marketing strategies of food and beverage companies across high-income, low- and middle-income countries. In order to assess how these companies use marketing techniques across different countries, this study aimed to: (1) use a qualitative codebook to identify the types of marketing techniques used on 18 international fast food and beverage company websites; (2) examine the nutritional quality of the products marketed on those websites; and (3) use descriptive statistics to compare the marketing strategies and nutritional quality of promoted products across high-income countries (HICs), upper middle income countries (UMICs), and lower-middle income countries (LMICs).

\section{Methods}

Six countries were chosen based on two criteria: 1) if McDonald's, Coca-Cola, and KFC have been selling products in their country for more than 20 years; and 2) if the countries met criteria to be categorized as a high-, upper-middle-, or lower-middle-income country. These economic categories were based on the three classifications available through the Organization for Economic
Co-Operation and Development (OECD): the United States and Germany (high income), China and Mexico (upper-middle-income), and India and the Philippines (lower-middle-income) [28]. Coca-Cola, McDonald's, and Kentucky Fried Chicken (KFC) were chosen for analysis because they have the largest global market share, represent the fastest growing international brands, and began in the United States [29-33]. We included the latter criterion because of the role many U.S. food companies play in contributing to the nutrition transition through their global food marketing and promotion practices [34, 35].

In order to qualitatively analyze the marketing techniques used on different international food and beverage company websites, two researchers developed a qualitative codebook based on the content analysis guidelines described by Lombard and colleagues [36]. The codebook questions were based on similar qualitative food marketing studies $[13,14,37,38]$ and were designed to examine the following marketing techniques on the international company websites: visual depictions of food or beverage products, the use of charity references or logos, references to exercise or physical activity, child targeted images or themes (i.e. images of children, cartoon characters, or words synonymous with "child") , product promotions, or culturally relevant images or symbols. After the codebook was developed, 10 research assistants who did not participate in codebook development and were blind to the purpose of the study took screenshots in June 2016 of the 18 websites' home pages and every page that could be accessed with one click from the website homepage. After compiling the screenshots, we trained four coders to view each screenshot and answer the codebook question based on the content shown in the screenshot. After training the coders, we randomly selected $10 \%$ of the total sample for the initial phase of coding that was needed in order to determine inter-coder reliability. An acceptable level of reliability was a Krippendorf's alpha coefficient of 0.70 or higher, or inter-coder agreement levels of $90 \%$ or higher. Because all four coders rated the same random $10 \%$ of data points (i.e. screenshots from each webpage) from the total sample in order to establish reliability, four sets of potential codes were available for those $10 \%$ of screenshots [36]. Specifically, this means that each coder rated the same 41 screenshots to ensure the coders were interpreting the questions in the same way. The fact that these four coders coded the same 41 screenshots means that there were four sets of responses for those screenshots. Lombard and colleagues describe four approaches to handling discrepancies in this initial $10 \%$ of codes [36]. One approach involves randomly selecting codes from these four sets to make one final set that is representative of the group. We chose this method because 
any discrepancies between coders would likely reflect discrepancies in the interpretation of general consumers, but would not affect the reliability of ratings because the coders met the reliability criteria. Additionally, the "majority rules" only applies to scenarios with odd numbers of coders, so that approach was not used. And using an expert to "tie-breaker" or having a group discussion to change responses would mean that the natural variability that could likely reflects consumers' variability in interpretations would be lost. Therefore, to ensure that a representative sample of these four sets of responses was integrated into the final data set, codes were randomly selected from these four sets. Thus, $10 \%$ of the final data set was made up of a random selection of codes from the reliability coding, and the remaining $90 \%$ of products were divided among four researchers and coded individually (Additional file 1: Figure S1). The dataset was analyzed using IBM Statistical Package for the Social Science (SPSS) version 23.0. We ran frequencies to determine the percentage of screenshots associated with each question in the qualitative codebook and chisquared tests to determine whether statistically significant differences occurred between companies and countries. Fisher's Exact Test was run when expected cell counts were too low for a chi-squared test.

In order to determine the healthfulness of each product endorsed on the websites, a nutrition score for each food product was generated from Nutrient Profile Model (NPM) [39, 40]. The NPM was selected because it was developed based on nutrition science and assigns a score to products based on nutrients to encourage (e.g. fiber) and nutrients to limit (e.g. sodium). It has been used in food marketing research focused on children and adults [38, $41,42]$ and front-of-package food labeling studies [43-45]. Higher scores represent less healthful products, whereas lower scores represent products with healthier qualities. In order to translate the NPM score to an easy-tounderstand scale, the final NPM score was converted to a Nutrient Profile Index (NPI), where 1 is the worst nutrition score and 100 is the best score. The NPI has been used in previous food marketing research [38, 41, 42]. The NPI uses the following formula: NPI score $=-2 \times$ NPM score +70 . A score $\geq 64$ is considered healthier. One limitation of the NPM is that it codes many sugar-sweetened beverages (SSBs) similarly because sugar is the only ingredient. A sugar-sweetened beverage is defined as any beverage with "added sugar" (i.e. any caloric sweetener added to the beverage during the production process), and NPM gives SSBs similar scores even if the amount of added sugar differs. To provide more meaningful descriptions of beverage categories, we coded nonalcoholic beverages into 11 drink categories, three sugary drink subcategories, and five other drink categories as outlined in the Rudd Center's Sugary Drink FACTS Report [46]. Drink categories included regular soda, fruit drinks, flavored water, sports drinks, iced tea, coffee, energy drinks, plain bottled water, $100 \%$ juice, diet drinks and light fruit juices. Drink subcategories included children's drinks, full-calorie drinks, and reduced-sugar drinks. Because nutrition information was not available on every website, we also sorted the foods on all websites into the following broad and mutually exclusive categories: (1) non-diet food or beverage product (e.g. burger and fries), and (2) diet food or beverage product (e.g. salad, chicken sandwich). Then we categorized those same products into mutually exclusive subcategories to provide finer detail: (1) fried (i.e. any product that appeared breaded or fried); (2) cooked (i.e. any product that was baked, grilled, or broiled but not fried); (3) fresh (i.e. any raw product, such as produce, that was neither fried nor cooked). The latter categorization enabled us to make comparisons across all websites even in the absence of nutritional information. Food products were also coded and sorted into three mutually exclusive food categories: main dishes, side items, and garnishes (i.e. fresh fruits and vegetables, herbs and spices, or grains) in the image.

\section{Results}

Across the 18 websites identified, we captured a total of 406 screenshots. Seven of the 18 websites displayed complete nutrition information for all products. Marketing techniques within brands varied between both individual countries and by the country's economic groups, and some marketing techniques varied between brands (Table 1). Initially, the NPI model was used to score the nutritional quality of the foods, but because 11 of the websites lacked nutrition information, we supplemented this analytic approach by categorizing foods shown in the screenshots as possessing component/s that were: (1) fried (i.e. any product that appeared breaded or fried); (2) cooked (i.e. any product that was baked, grilled, or broiled but not fried); (3) fresh (i.e. any raw product, such as produce, that was neither fried nor cooked) (Table 2).

\section{Comparisons between economic groupings across all three companies}

High-income countries' websites promoted a diet/ healthy food (e.g. baked chicken sandwich) or beverage product on $25 \%(N=22)$ of their pages, compared to $11.2 \%(N=17)$ of the UMICs websites and $14.5 \%$ $(N=24)$ of the LMICs websites. Promotions were featured more often on webpages in HICs (12.5\%) and UMICs (12.5\%) than LMICs (6.6\%). Across all three brands, links promoting a children's section of the website appeared most frequently on UMICs' websites. On average, links to a children's section or promotional material directed at children (e.g. an image or text reference to children or cartoon characters) appeared on $4.6 \%$ 


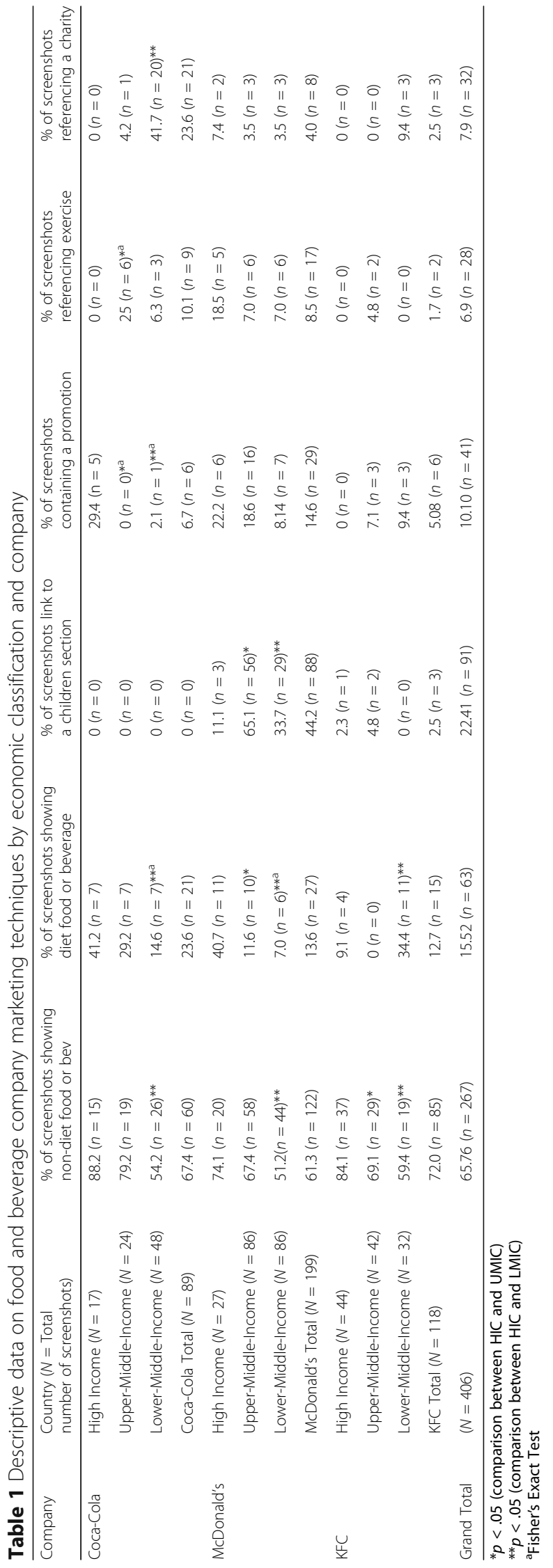




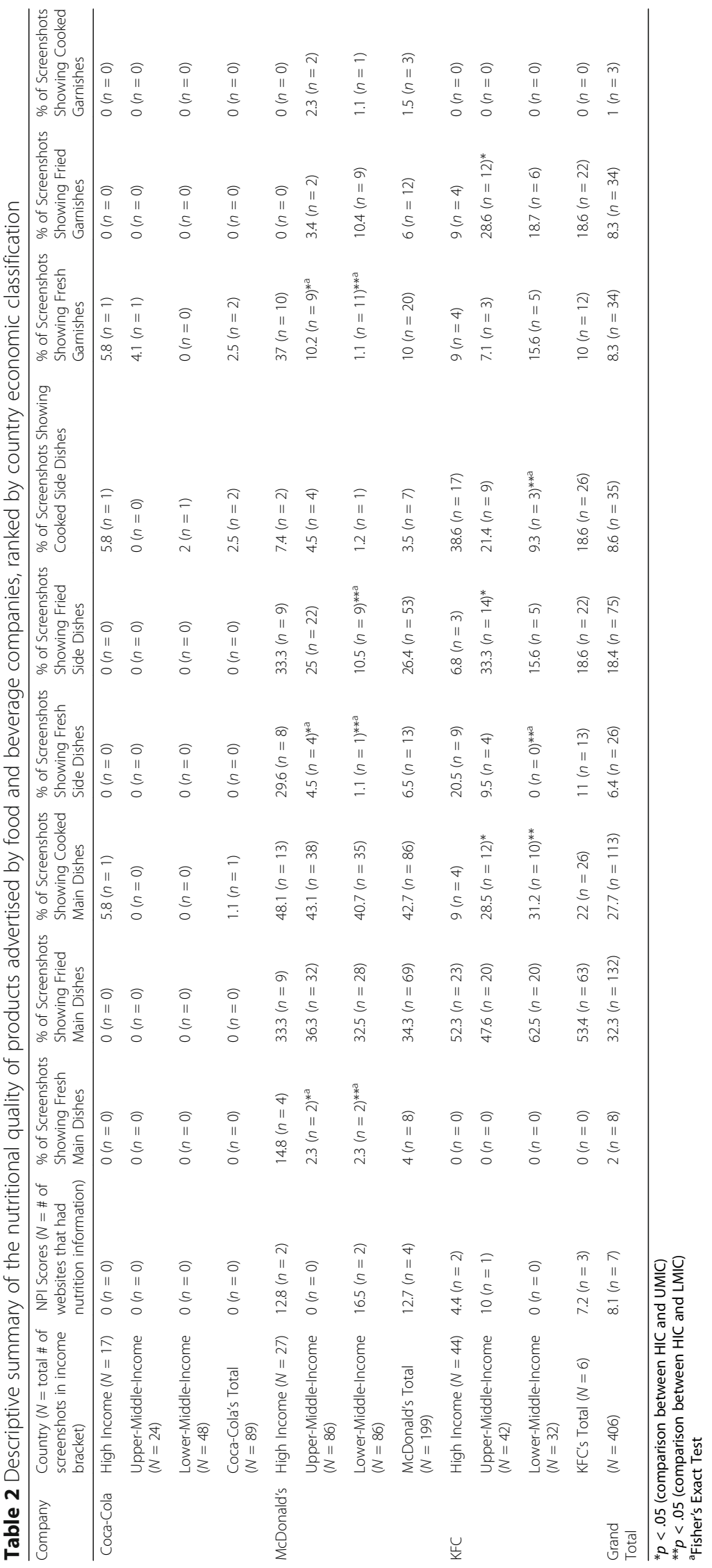


$(N=4)$ of HICs' webpages, compared to $38.2 \%(N=58)$ of UMICs' webpages and $17.7 \%(N=29)$ in LMICs' webpages. LMICs' webpages were the most likely to reference a charity $(15.7 \%, N=26)$ compared to UMICs $(2.6 \%, N=4)$ and HICs $(2.3 \%, N=2)$. The proportion of webpages referencing a charity was significantly different between LMICs and UMICs $(p<0.001)$ as well as between LMICs and HICs $(p=0.001)$. Researchers also found some similarities in marketing techniques across economic groupings. More than $50 \%(N=267)$ of all webpages showed any food or beverage product (i.e. diet or non-diet), and less than $10 \%$ of all countries' webpages referenced exercise or sports.

Fried main dishes were featured similarly across country economic groupings, while fresh main dishes (e.g. salads) were rarely featured on any website $(N=8)$. Furthermore, cooked main dishes were featured more frequently on UMICs websites. Fresh side dishes and garnishes were featured more frequently on HICs websites, while fried side dishes were featured more frequently on UMICs websites and fried garnishes were most frequently featured on LMIC's websites (Table 2).

\section{Comparing different countries' websites within the same parent company}

An analysis of Coca-Cola's marketing strategies showed that the ratio of SSBs to diet beverages differed between each economic country group. In the HICs, $88.2 \%$ $(N=15)$ of the webpages showed SSBs while $41 \cdot 2 \%$ $(N=7)$ of the webpages promoted diet versions of beverages. Seventy-nine percent $(N=19)$ of the webpages in UMICs advertised sugar-sweetened beverages while $29.2 \%(N=7)$ promoted a diet beverage. In LMICs, $54 \cdot 2 \%(N=26)$ of Coca-Cola's webpages advertised sugar-sweetened beverages, while $14.6 \%(N=7)$ promoted diet options. Taken together, the difference between how many times diet beverages versus SSBs appeared was narrower in HIC websites (where the split was $88 \%$ SSB versus $41 \%$ diet), whereas in UMIC and LMIC websites, the gap was wider (54\% SSBs versus $14 \%$ diet) suggesting diet products are promoted less frequently to LMICs via these websites. The number of screenshots depicting diet alternatives was statistically significantly higher in HICs as compared to LMICs.

Within the McDonald's company, fresh main dishes were advertised significantly more frequently on HIC websites (14.8\%) than on UMIC and LMIC websites ( $2.3 \%$ each). Furthermore, fresh side dishes were marketed on $29.6 \%$ of the webpages in HICs, $4.5 \%$ in UMICs, and $1.1 \%$ in LMICs; these differences were also statistically significant. Diet products or healthy alternatives to standard fast food products were not offered at similar rates across country websites. Fifty-one percent of the LMICs' webpages showed food or beverages, yet only $7 \%$ of these pages promoted diet products. Similarly, $67 \%$ of the UMICs' webpages advertised food or beverages, and just $11.6 \%$ showed diet options. In comparison, $74 \%$ of the HICs webpages showed food or beverages while diet options were promoted on $40.7 \%$ of the webpages. The percentage of websites showing diet products or healthy alternatives was significantly different between HIC and UMIC as well as between HIC and LMIC. In addition to the variations between food marketing, $18.5 \%$ of the webpages in HICs referenced exercise or sports compared to $7.0 \%$ in UMICs, and $7.0 \%$ in LMICs.

Similar to Coca-Cola and McDonald's, KFC promoted any food and beverages on a high percentage of its webpages. Although KFC's webpages among all of the economic country groups did not advertise any fresh main dishes, $20.5 \%$ of HIC webpages promoted a fresh side dish, compared to $9.5 \%$ of UMIC webpages and $0 \%$ of LMIC pages. KFC webpages contained promotions on $7.1 \%$ of UMIC webpages, compared to $9.4 \%$ of LMIC webpages. No promotions were offered on HIC webpages.

\section{Discussion}

In this study, we found that all three fast food and beverage companies promoted diet food or beverage products and fresh main dishes more frequently on their websites in HICs than in the UMICs and LMICs. However, fried main dishes and fried side dishes were displayed at similar rates across high-income countries. Promotions (e.g. free cell phone minutes) appeared more frequently on HICs and UMICs websites, and nutritional information was found on less than $40 \%$ of websites across all economic classifications. LMICs' webpages were the most likely to reference a charity $(15 \cdot 7 \%, N=26)$ compared to UMICs $(2 \cdot 6 \%, N=4)$ and HICs $(2 \cdot 3 \%, N=2)$. These findings suggest that companies promote fewer healthful products on their websites in lower-income populations while simultaneously highlighting their philanthropic activities to appeal to consumers in lower income countries. When comparing the practices of each company, Coca-Cola promoted diet beverages less frequently in lower income countries. The most striking contrast occurred with McDonald's because half of the foods promoted on HIC websites were diet/healthy options, whereas just $6 \%$ of UMIC websites promoted healthy options on McDonald's sites, and zero LMIC websites included diet/healthy options. Similarly, McDonald's promoted more fresh main dishes on HIC websites compared to lower income country websites, and none of the web pages on LMIC websites showed diet products. A similar contrast appeared with KFC's use of fresh side dishes on websites across different economic groupings. These differences in promotion of unhealthy food and SSBs are concerning because they 
occur in the context of the increasing burden of chronic diseases globally, with $77 \%$ of the world's diabetic population residing in low- and middle-income countries [47]. In regards to physical activity messages, McDonald's promoted exercise imagery more often on LMIC websites than their HIC websites. These messages, while important, need to be paired with healthy food messaging in part because research has shown that consumers perceive athlete-endorsed food as healthier than nonendorsed food [48]. Such messages create a "halo effect" in which consumers underestimate calories of food due to their marketing claims or visual appearance [49].

While no studies have compared the marketing techniques on food and beverage company websites across countries of varying economic status, other studies have examined the nutritional content of products promoted on websites. Previously published research on food websites have been mainly conducted in the US and have mostly focused on child-targeted content. Studies found that the majority of food and beverage products advertised on children's websites are unhealthy [9-11]. Advergames websites (i.e. sites that offer online games branded with company logos) $[7,8]$ and cereal websites [12] also primarily promote unhealthy and sugary foods. In fact, Ustjanauskas et al. found that $84 \%$ of ads on popular children's websites show products high in fat, sugar, and/or sodium [9]. Lingas et al. found that only five out of 77 food and beverage products advertised on popular children's websites met the Institute of Medicine guidelines for foods to promote to youth [10]. In terms of methods, food advertising on websites use branded engagement techniques and themes of identity formation to specifically capture the attention of children [50].

Our findings were similar to some previously published research on website-based food marketing in that the majority of products promoted were energy-dense, nutrient-poor products, and companies used a variety of promotional techniques. However, our results show fewer child-targeted marketing practices than those studies, likely because a number of those studies focused specifically on child-targeted advergames. The inclusion of corporate websites that are owned by the same parent company but span a variety of countries from different economic groups is a strength of this study because it enabled us to compare the different promotional techniques across countries and within each company. Indeed, this is the first study to our knowledge to identify some differences in website-based marketing techniques across higher and lower income countries within the same parent companies. Still, the current study is limited by the possibility that researchers missed some marketing techniques or cooking methods shown on the webpages. Furthermore, the screenshots were taken of only six countries' websites, limiting our ability to make broader conclusions about these companies' international food and beverage marketing techniques. Lastly, because we did not experimentally assess the influence of advertised food and beverage products on consumer or health behaviors, the relationship between purchase behaviors or consumption behaviors with website content cannot be determined from these data.

Future research should examine international digital food marketing by broadening the number of countries and companies examined and by comparing the marketing techniques and nutritional quality of products promoted on food companies' international social media accounts. Similar to the way food companies maintain official websites for different country, many companies have social media accounts on Twitter and Facebook that are specific to different countries. It is unclear how many youth engage with food companies' social media accounts, suggesting a need for thorough surveillance data that could inform the extent to which companies should participate in uniform guidelines about marketing to youth through social media [51]. For example, self-regulatory efforts include the International Chamber of Commerce Guidelines on Advertising, Federation of European Direct Marketing Code on E-Commerce and Interactive Marketing, and the European Group on Television Advertising (EGTA) Guidelines for Commercial Communications on New Interactive Services are all designed to eliminate the risk of harm or exploitation of youth online and could be useful models for implementing uniform guidelines. Regulating digital marketing is complex because of cross-border marketing, [51] but critical for reducing youth exposure to unhealthy food and beverage ads.

One other notable finding that was not part of our aims involves the lack of nutritional information available on McDonald's Philippines website despite being present elsewhere. Additionally, McDonald's in India is divided into two separate sites; one for the historically wealthier south and one for the rural and historically poorer north [52]. There were several notable discrepancies in the marketing techniques used on the two McDonald's India websites: while $100 \%$ of northern India pages contained promotional material aimed at children, only $13 \%$ of southern India pages contained such material. In addition, $50 \%$ of southern India pages showed a fresh main dish while only $13 \%$ of northern India pages showed a fresh main dish.

\section{Conclusions}

This study finds that some fast food and beverage companies are marketing healthier products in wealthier countries and showcasing their philanthropic activities in lower income countries. Overall, economic globalization has enabled food and beverage marketers to introduce a variety of reasonably priced, [53] 
culturally resonant products and market them to responsive audiences, but these companies should also take responsibility for the influence their products can have on the populations they target. These findings can be used to guide the development of policies to address the growth of fast food and beverage marketing in developing and emerging markets in LMICs and UMICs. Policymakers could consider prohibiting the use of certain marketing techniques in their countries or advocate for the promotion and sale of healthier food and beverage products.

\section{Additional file}

Additional file 1: Figure S1. Overview of Qualitative Content Analysis Coding Process. Flow chart explaining the coding process. (PDF $123 \mathrm{~kb}$ )

\section{Abbreviations}

HIC: High income country; KFC: Kentucky Fried Chicken; LMIC: Lower-middleincome country; NPI: Nutrient Profile Index; NPM: Nutrient Profile Model; OECD: Organization for Economic Co-Operation and Development; SSB: Sugar sweetened beverage; UMIC: Upper-middle-income country

\section{Acknowledgements}

Samina Lutfeali, Ruchi Desai, Maimuna Marenah, Scott Hughes, Greg Vann, Susan Stork, Anna Davies, Sally Slingerland, Alexia Akbay, Erin Rhodes, DiAnna Brice, and Tenay Greene.

\section{Funding}

Dr. MB is supported by a grant from the NIH Office of the Director (DP5OD021373-01). The NIH Office of the Director had no role in the design of the study, the collection, analysis, or interpretation of data, or in the writing of the manuscript.

\section{Availability of data and materials}

The datasets used and/or analyzed during the current study are available from the corresponding author on reasonable request.

\section{Authors' contributions}

Dr. MB originated the idea for the manuscript, drafted the manuscripts, and approved the final manuscript as submitted. Ms. ME assisted with data collection and analysis and helped with the development of the manuscript. Mr. JA assisted with data collection and analysis and helped with the development of the manuscript. Ms. AB and Dr. GO provided critical feedback on drafts of the manuscript and assisted in framing the issues. All authors approved the final manuscript as submitted and agree to be accountable for all aspects of the work

\section{Ethics approval and consent to participate}

Not applicable.

\section{Consent for publication}

Not Applicable.

Competing interests

The authors declare that they have no competing interests.

\section{Publisher's Note}

Springer Nature remains neutral with regard to jurisdictional claims in published maps and institutional affiliations.
Received: 5 June 2017 Accepted: 5 October 2017

Published online: 26 October 2017

\section{References}

1. Drewnowski A. Obesity, diets, and social inequalities. Nutr Rev. Wiley Online Library. 2009;67(Suppl 1):S36-9.

2. Seiders K, Petty RD. Obesity and the role of food marketing: a policy analysis of issues and remedies. J Public Policy Mark. American Marketing Association. 2004;23:153-69.

3. Harris $J$, Pomeranz $J$, Lobstein T, Brownell KD. A crisis in the marketplace: how food marketing contributes to childhood obesity and what can be done. Annu Rev Public Health. 2009;30:211-25.

4. Cairns G, Angus K, Hastings G, Caraher M. Systematic reviews of the evidence on the nature, extent and effects of food marketing to children: a retrospective summary. Appetite. 2013;62:209-15.

5. Ignatius A. Shaking Things Up at Coca-Cola [Internet]. Harvard Business Review. 2011. Available from: https://hbr.org/2011/10/shaking-things-up-atcoca-cola. [cited 18 Sep 2017].

6. Perrin A. One-fifth of Americans report going online "almost constantly" [Internet]. Pew Research Center. 2015. Available from: http://www. pewresearch.org/fact-tank/2015/12/08/one-fifth-of-americans-report-goingonline-almost-constantly/. [cited 18 Sep 2017].

7. Harris JL, Speers SE, Schwartz MB, Brownell KD. US food company branded Advergames on the internet: Children's exposure and effects on snack consumption. J Child Media. Routledge. 2012;6:51-68.

8. Dias M Agante L. Can advergames boost children's healthier eating habits? A comparison between healthy and non-healthy food. J Consumer Behav. John Wiley \& Sons, Ltd. 2011;10:152-60.

9. Ustjanauskas $A E$, Harris $J$, Schwartz MB. Food and beverage advertising on children's web sites. Pediatr Obes. 2014;9:362-72.

10. Lingas EO, Dorfman L, Bukofzer E. Nutrition content of food and beverage products on web sites popular with children. Am J Public Health. 2009;99(Suppl 3):S587-92.

11. Kelly B, Bochynska K, Kornman K, Chapman K. Internet food marketing on popular children's websites and food product websites in Australia. Public Health Nutr. 2008;11:1180-7.

12. Cheyne AD, Dorfman L, Bukofzer E, Harris JL. Marketing sugary cereals to children in the digital age: a content analysis of 17 child-targeted websites. Jealth Commun. 2013:18:563-82.

13. Weber K, Story M, Harnack L. Internet food marketing strategies aimed at children and adolescents: a content analysis of food and beverage brand web sites. J Am Diet Assoc. 2006;106:1463-6.

14. Henry AE, Story M. Food and beverage brands that market to children and adolescents on the internet: a content analysis of branded web sites. J Nutr Educ Behav. 2009:41:353-9.

15. Montgomery KC, Chester J, Grier SA, Dorfman L. The new threat of digital marketing. Pediatr Clin N Am. 2012;59:659-75. viii

16. Freeman B, Kelly B, Baur L, Chapman K, Chapman S, Gill T, et al. Digital junk: food and beverage marketing on Facebook. Am J Public Health. ajph. aphapublications.org. 2014;104:e56-64.

17. Folkvord F, Anschütz DJ, Buijzen M, Valkenburg PM. The effect of playing advergames that promote energy-dense snacks or fruit on actual food intake among children. Am J Clin Nutr. 2013;97:239-45.

18. Ritzer G, Dean P. Globalization: a basic text. 2nd ed. New Jersey: WileyBlackwell; 2015.

19. Gibbs A. McDonald's eyes greater restaurant expansion in Asia [Internet]. CNBC 2016. Available from: https:/www.cnbc.com/2016/03/31/mcdonalds-eyesgreater-restaurant-expansion-in-china-hong-kong-korea.html. [cited 21 Feb 2017].

20. Chalabi M, Burn-Murdoch J. McDonald's 34,492 restaurants: where are they? [Internet]. The Guardian. 2013. Available from: https://www.theguardian. com/news/datablog/2013/jul/17/mcdonalds-restaurants-where-are-they. [cited 21 Feb 2016].

21. Stynes T. Coca-Cola Plans to Spend Additional \$5 Billion in Africa [Internet]. The Wall Street Journal. 2015. Available from: https://www.wsj.com/articles/ coca-cola-plans-to-spend-additional-5-billion-in-africa-1407256018. [cited 1 Feb 2016]

22. Gulati N, Ahmed R. India Has 12 Billion People but Not Enough Drink Coke [Internet]. The Wall Street Journal. 2012. Available from: https://www.wsj. com/articles/SB10001424052702304870304577490092413939410. [cited 1 Feb 2016] 
23. Ng M, Fleming T, Robinson M, Thomson B, Graetz N, Margono C, et al. Global, regional, and national prevalence of overweight and obesity in children and adults during 1980-2013: a systematic analysis for the global burden of disease study 2013. Lancet. 2014;384:766-81.

24. De Vogli R, Kouvonen A, Gimeno D. "Globesization": ecological evidence on the relationship between fast food outlets and obesity among 26 advanced economies. Crit Public Health. Taylor \& Francis. 2011;21:395-402.

25. Population nutrient intake goals for preventing diet-related chronic diseases [Internet]. World Health Organization. Available from: http://www.who.int/ nutrition/topics/5_population_nutrient/en/index4.html. [cited 1 Feb 2016].

26. Mackay J, Crofton J. Tobacco and the developing world. Br Med Bull. 1996:52:206-21.

27. Nesheim MC, Nestle M. The internationalization of the obesity epidemic In: Sahn DE, editor. The fight against hunger and malnutrition: New York: Oxford University Press; 2015

28. OECD Income Distribution Database (IDD): Gini, poverty, income, Methods and Concepts [Internet]. OECD. 2017. Available from: http://www.oecd.org/ social/income-distribution-database.htm. Accessed 1 Mar 2017.

29. Smith AF. Encyclopedia of junk food and fast food. Westport: Greenwood Publishing Group; 2006.

30. World Bank Country and Lending Groups [Internet]. The World Bank. 2016. Available from: https://datahelpdesk.worldbank.org/knowledgebase/articles/ 906519. [cited 1 Jul 2016].

31. Top 10 Global Fast Food Chains [Internet]. Forbes. 2016. Available from: https://www.forbes.com/pictures/mlf45mkjl/top-10-global-fast-food-brands2/\#459464736dc7. [cited 1 Jul 2016].

32. The Global 30 [Internet]. QSR. 2012. Available from: https://www. qsrmagazine.com/content/global-30. [cited 1 Jul 2016].

33. McGrath M. The World's Largest Food And Beverage Companies 2016 : Chocolate, Beer And Soda Lead The List [Internet]. Forbes. 2016. Available from: http://www.forbes.com/sites/maggiemcgrath/2016/05/27/the-worldslargest-food-and-beverage-companies-2016-chocolate-beer-and-soda-leadthe-list/\#37268c7c7194. [cited 1 Jul 2016].

34. Popkin BM, Gordon-Larsen P. The nutrition transition: worldwide obesity dynamics and their determinants. Int J Obes Relat Metab Disord. 2004;28(Suppl 3):S2-9.

35. Hawkes C. Globalization, food and nutrition transitions. Globalization and health knowledge network: research papers: WHO Commission on Social Determinants of Health. University of Ottawa: Institute of Population Health; 2007.

36. Lombard M, Snyder-Duch J, Bracken CC. Content analysis in mass communication: assessment and reporting of Intercoder reliability. Hum Commun Res. Blackwell Publishing Ltd. 2002;28:587-604.

37. Manganello JA, Clegg Smith K, Sudakow K, Summers AC. A content analysis of food advertisements appearing in parenting magazines. Public Health Nutr. 2013;16:2188-96

38. Bragg MA, Liu PJ, Roberto CA, Sarda V, Harris JL, Brownell KD. The use of sports references in marketing of food and beverage products in supermarkets. Public Health Nutr. 2013;16:738-42.

39. Rayner M, Scarborough P, Boxer A, Stockley L. Nutrient profiles: development of Final model. London: Food Standards Agency [Internet]. 2005. Available from: https://www.researchgate.net/profile/Peter_ Scarborough/publication/266447771_Nutrient_profiles_Development_of_ Final_Model_Final_Report/links/5440d4fe0cf218719077d82d.pdf. Accessed 1 Mar 2017.

40. Scarborough P, Boxer A, Rayner M. Testing nutrient profile models using data from a survey of nutrition professionals. Public Health Nutr. [Internet]. cambridge.org; 2007. Available from: https:/www.cambridge.org/core/journals/ public-health-nutrition/article/testing-nutrient-profile-models-using-data-from-asurvey-of-nutrition-professionals/5BDF8ABE7F1A48A352FBEEE079F11A88. Accessed 1 Mar 2017.

41. Bragg MA, Miller AN, Elizee J, Dighe S, Elbel BD. Popular Music Celebrity Endorsements in Food and Nonalcoholic Beverage Marketing. Pediatrics [Internet]. 2016;138. Available from: https://doi.org/10.1542/peds.2015-3977. Accessed 1 Mar 2017.

42. Bragg MA, Yanamadala S, Roberto CA, Harris JL, Brownell KD. Athlete endorsements in food marketing. Pediatrics. 2013;132:805-10.

43. Roberto CA, Bragg MA, Seamans MJ, Mechulan RL, Novak N, Brownell KD. Evaluation of consumer understanding of different front-of-package nutrition labels, 2010-2011. Prev Chronic Dis. 2012;9:E149.
44. Roberto CA, Bragg MA, Livingston KA, Harris JL, Thompson JM, Seamans MJ, et al. Choosing front-of-package food labelling nutritional criteria: how smart were "smart choices"? Public Health Nutr. 2012;15:262-7.

45. Roberto CA, Bragg MA, Schwartz MB, Seamans MJ, Musicus A, Novak N, et al. Facts up front versus traffic light food labels: a randomized controlled trial. Am J Prev Med. 2012:43:134-41.

46. Harris JL, Schwartz MB, Brownell KD, Javadizadeh J, Weinberg M, Sarda V, et al. Sugary drink FACTS: Food advertising to children and teens score. New Haven, CT: Yale Rudd Center for Food Policy and Obesity. 2014. Online at http://www.sugarydrinkfacts.org/resources/SugaryDrinkFACTS_Report.pdf. Accessed 10 Mar 2011

47. Hu FB, Satija A, Manson JE. Curbing the diabetes pandemic: the need for global policy solutions. JAMA. 2015;313:2319-20.

48. Dixon H, Scully M, Wakefield M, Kelly B, Chapman K, Donovan R. Parent's responses to nutrient claims and sports celebrity endorsements on energy-dense and nutrient-poor foods: an experimental study. Public Health Nutr. 2011;14:1071-9.

49. Chernev A, Chandon P. Calorie estimation biases in consumer choice. Leveraging consumer psychology for effective health communications: the obesity challenge, vol. 104. NY: ME Sharpe Armonk; 2010. p. 21.

50. Schor JB, Ford M. From tastes great to cool: children's food marketing and the rise of the symbolic. J Law Med Ethics. 2007;35:10-21.

51. Hawkes C. Marketing food to children [electronic resource]: changes in the global regulatory environment, 2004-2006. World Health Organization; 2007. Accessed 1 Mar 2017.

52. Sabnavis M. The new "Two Indias" [Internet]. Business Standard. 2013. Available from: http://www.business-standard.com/article/opinion/madhukar-sabnavisthe-new-two-indias-113120501027_1.html. [cited 4 Aug 2016].

53. Witkowski TH. Food marketing and obesity in developing countries: analysis, ethics, and public policy. J Macromarketing. SAGE Publications Inc. 2007:27:126-37.

\section{Submit your next manuscript to BioMed Central and we will help you at every step:}

- We accept pre-submission inquiries

- Our selector tool helps you to find the most relevant journal

- We provide round the clock customer support

- Convenient online submission

- Thorough peer review

- Inclusion in PubMed and all major indexing services

- Maximum visibility for your research

Submit your manuscript at www.biomedcentral.com/submit 